\title{
PANORAMA DA PRODUÇÃO DO CONHECIMENTO EM ATIVIDADE FÍSICA ADAPTADA NOS PROGRAMAS DE PÓS-GRADUAÇÃO EM EDUCAÇÃO FÍSICA DO ESTADO DO PARANÁ
}

\author{
Tabea $\in p p$ Kuster Alves' \\ Rafael Estevam Reis ${ }^{2}$ \\ Marcelo Moraes e Silva ${ }^{3}$
}

\section{RESUMO}

No estado do Paraná, são quatro as Instituições de Ensino Superior, indicadas pela CAPES, que possuem programas de pós-graduação stricto sensu em Educação Física. Com o objetivo de conhecer a produção relacionada à atividade física adaptada no Paraná e compreender os caminhos que ela tem seguido, mapearam-se nestes programas todas as dissertações e teses relacionadas à temática. Ao todo, foram encontradas 17 pesquisas, 15 dissertações e 2 teses. Quanto ao tipo de deficiência, são estudadas em maior número atividades voltadas a indivíduos com deficiência física, intelectual e visual, sendo que nenhuma exclusivamente com pessoas com deficiência auditiva foi encontrada. Ao pesquisar o currículo dos autores, concluiu-se que a maioria dos produtores das dissertações e teses tem envolvimento no "universo" para-desportivo e apresenta a tendência de pesquisar e publicar somente nesta área, ao contrário dos orientadores, em que somente a minoria é envolvida com a temática.

Palavras-chave: Pós-graduação. Atividade física adaptada. Pesquisa

1 Graduação em Educação Física. Mestranda em Educação Física na Universidade Federal do Paraná (UFPR). Curitiba/Paraná, Brasil. E-mail: tabeaepp@hotmail.com

2 Mestre em Educação Física. Doutorando em Educação Física na Universidade Federal do Paraná (UFPR). Curitiba/Paraná, Brasil. E-mail: rafael_e_reis@hotmail.com

3 Doutor em Educação. Professor da Universidade Federal do Paraná (UFPR). Curitiba/Paraná, Brasil.

E-mail: moraes_marc@yahoo.com.br 


\title{
THE PRODUCTION OF KNOWLEDGE IN PHYSICAL ACTIVITY ADAPTED IN THE POST-
} -GRADUATION PROGRAMS IN PHYSICAL EDUCATION OF THE STATE OF PARANÁ

\begin{abstract}
In Paraná State, there are four Institutions of Higher Education, indicated by CAPES, that have post-graduate programs stricto sensu in Physical Education. In order to know the production related to the Adapted Physical Activity in Paraná and to understand the paths that it has followed, all dissertations and theses related to the theme have been mapped in these programs. In all, 17 researches, 15 dissertations and 2 theses were found. Regarding the type of disability, a greater number of activities are studied for individuals with physical, intellectual and visual disabilities, none of whom are exclusively hearing impaired. In studying the authors' curriculum, it was concluded that most of the authors of dissertations and theses have some involvement in the parasport "universe", and that they tend to research and publish only in this area, unlike the advisors where only the minority is involved with the theme.
\end{abstract}

Key words: Post-graduation. Adapted physical activity. Research

\section{PRODUCCIÓN DE CONOCIMIENTO EN LA ACTIVIDAD FÍSICA ADAPTADA EN PROGRAMAS DE POSTGRADO EN EDUCACIÓN FÍSICA DEL ESTADO DE PARANÁ}

\section{RESUMEN}

En el estado de Paraná, son cuatro las instituciones de educación superior, indicados por la CAPES, que tienen programas de postgrado stricto sensu en la Educación Física. Con el fin de conocer la producción relacionada con la Actividad Física Adaptada en Paraná y comprender las formas en que ha seguido, esbozó en estos programas de todas las disertaciones y tesis relacionadas con el tema. En total se encontraron 17 estudios, 15 disertaciones y 2 tesis. En cuanto al tipo de discapacidad, que se estudian en más números actividades dirigidas a las personas con discapacidades físicas, intelectuales y visuales, y ninguno exclusivamente a las personas con discapacidad auditiva fue encontrado. Al buscar en el currículum de los autores, se concluyó que la mayoría de los productores de disertaciones y tesis tienen participación en el "universo" para actividades deportivas y muestran una tendencia a investigar y publicar sólo en esta área, a diferencia de los orientadores donde sólo una minoría está implicado con el tema.

Palabras claves: Pos graduación. Actividad física adaptada. Investigación 


\section{INTRODUÇÃO}

O aumento do percentual da população brasileira com deficiência, as leis e ações que asseguram os direitos das pessoas com deficiência (PCD), as modificações na arquitetura das cidades gerando acessibilidade, a inclusão de crianças com deficiência em escolas regulares, o crescimento do número de atletas paralímpicos e os ótimos resultados dos mesmos em competições - como Jogos Paralímpicos e Parapanamericanos - são elementos que têm fortalecido o aumento da demanda de ações, projetos, planejamentos pedagógicos e políticas públicas voltados à PCD no Brasil (GORLA, 2008; SILVA; SEABRA JÚNIOR; ARAÚJO, 2008; REIS, 2014; PEREIRA DA SILVA, 2015).

Esta demanda, conforme apontam Gorla (2008) e Silva; Seabra Júnior; Araújo (2008), passou a exigir dos profissionais de Educação Física um melhor preparo e o uso de instrumentos e estratégias adaptadas, consequentemente, como indicam Silva; Araújo (2012), a pesquisa e a produção do conhecimento sobre os mesmos se mostrou necessária. No Brasil, os termos pesquisa e produção de conhecimento aludem, conforme apontam Manoel; Carvalho (2011), Pereira da Silva; Gonçalves-Silva; Moreira (2014) e Souza; Moraes e Silva; Moreira (2016), Moraes e Silva et al. (2017), aos Programas de Pós-Graduação, principalmente aos que ofertam cursos de mestrado e doutorado.

Na área da Educação Física no Brasil a pós-graduação é algo relativamente recente. Segundo argumentam Rigo; Ribeiro; Hallal (2011) os primeiros cursos de mestrado em Educação Física remetem ao final da década de 1970. Os autores lembram que em 1980 a área contava com 2 programas de mestrado e nenhum de doutorado. Em 1990, tais números mudaram para 7 e 1, respectivamente. Em 2000, os cursos eram 12 de mestrado e 7 de doutorado. Já em 2010, existiam 21cursos de mestrado e nove de doutorado (RIGO; RIBEIRO; HALLAL, 2011). Atualmente são 37 os Programas de Pós-Graduação em Educação Física que oferecem título de mestrado, destes, 22 possuem curso de doutorado (CAPES, 2016). Rigo, Ribeiro; Hallal (2011) lembram que apesar da trajetória histórica ser de certa forma recente, a reflexão sobre o desenvolvimento e a direção que a pós-graduação tem tomado no Brasil são elementos fundamentais para o aprimoramento do fazer ciência em Educação Física.

Diante das diversidades epistemológicas apresentadas pela Educação Física no Brasil (RIGO; RIBEIRO; HALLAL, 2011; ROSA; LETA, 2011; TAVARES, 2015) é importante que também sejam realizadas reflexões em "fragmentos", dividida por temáticas (SILVA; ARAÚJO, 2012; GARCIA, 2014), e/ou por recortes espaciais (SORIANO; LARA, 2012; MIRANDA; BOMFIM; SANTOS SILVA, 2013; FURTADO; NAMAM, 2014). Tais procedimentos podem contribuir para que se obtenha uma análise mais abrangente sobre a temática da produção do conhecimento e sua relação com os Programas de Pós-Graduação. Nesse sentido, uma das temáticas que necessita ser abordada é a da Atividade Física Adaptada (AFA). Sendo assim, o presente artigo busca responder a seguinte problemática de pesquisa: qual o atual panorama da produção do conhecimento em AFA dentro dos Programas de Pós-Graduação em Educação Física no Estado do Paraná? 
Desse modo, o objetivo geral do presente trabalho é traçar o atual panorama da produção do conhecimento em AFA nos Programas de Pós-Graduação em Educação Física do Estado do Paraná. Por sua vez os objetivos específicos do artigo são os seguintes: a) mapear as dissertações e teses defendidas nestes programas; b) compreender o perfil dos principais agentes envolvidos nestas produções.

\section{METODOLOGIA}

O presente estudo deve ser considerado, segundo aponta Gil (1999) como qualitativo documental. Nesta tipologia de pesquisa, os documentos podem ser classificados em dois tipos, que são as fontes de primeira e de segunda mão. As primeiras são aquelas que não receberam, até então, qualquer tratamento analítico. Já as de segunda mão são aquelas que já foram analisados de alguma maneira por outros pesquisadores. Diante desta exposição, pode-se afirmar que os documentos aqui analisados são basicamente compostos por fontes de primeira mão.

Baseou-se nos artigos publicados anteriormente por Manoel; Carvalho (2011), Pereira da Silva; Gonçalves-Silva; Moreira (2014) e Souza; Moraes e Silva; Moreira (2016) para amparar a premissa de que a maior parte da produção científica em Educação Física ocorre dentro dos Programas de Pós-Graduação e que as dissertações e teses de mestrandos e doutorandos são base para artigos e/ou outros tipos de produções científicas. São estes elementos que levaram à escolha de analisar as dissertações e teses oriundas dos programas localizados no Estado do Paraná.

Uma das maiores dificuldades encontradas no processo de discussão relacionado às práticas corporais e os indivíduos com deficiência é justamente a questão da padronização da terminologia utilizada, visto que não existe uma nomenclatura considerada "certa" ou "errada" (ARAÚJO, 1997; WINNICK, 2004; GORLA, 2008; SILVA; SEABRA JÚNIOR; ARAÚJO, 2008). Existem opções que variam de acordo com cada autor e de suas bases epistemológicas. Embora parecidas, tais nomenclatura não têm necessariamente o mesmo significado e/ou finalidade. Algumas das terminologias mais utilizadas são: Educação Física Adaptada, Atividade Física Adaptada, Atividade Motora Adaptada, Esporte Paraolímpico, Esporte Paralímpico, Esporte Adaptado e Paradesporto (ARAÚJO, 1997; GORLA, 2008; SILVA; SEABRA JÚNIOR; ARAÚJO, 2008; WINNICK, 2004).

Segundo Araújo (1997) Atividade Adaptada é quando se busca adequar meios para chegar a um objetivo, uma vez que os meios tradicionais não se mostram suficientes e/ou eficientes para o mesmo fim. O autor salienta que o Esporte Adaptado por sua vez refere-se à adaptação nas regras de uma modalidade já conhecida e praticada pela população. Já o termo Esporte Paralímpico, segundo aponta Reis (2014), refere-se às modalidades que fazem parte do programa dos Jogos Paralímpicos.

Diante de tantas nomenclaturas possíveis, utilizou-se por fins metodológicos, todos os termos acima citados no momento de realizar a busca por teses e dissertações nos bancos de dissertações e teses das universidades selecionadas. Porém, para a discussão do presente 
artigo, optou-se por utilizar o termo mais amplo Atividade Física Adaptada (AFA), pois se entende que algumas pesquisas não tratam necessariamente do esporte, e mesmo assim, são relacionados à atividade física e o indivíduo com deficiência. Seguindo os preceitos estabelecidos pelo congresso mundial da IFAPA (Federação Internacional de Atividade Física Adaptada), Souza (2006) afirma que AFA é a atividade dirigida aos interesses e às capacidades para a atividade física, movimento e esporte, por pessoas com condições alteradas, como aqueles com deficiência e/ou limitações em sua saúde.

O recorte do estado do Paraná foi pensando pela possibilidade de um aprofundamento nas pesquisas e nos pesquisadores, permitindo assim uma análise mais pormenorizada das produções e autores em questão. Ao buscar na Plataforma Sucupira, as Universidades localizadas no Estado do Paraná que apresentam programas de Pós-Graduação em Educação Física recomendados pela CAPES encontrou-se as seguintes instituições: Universidade Estadual de Maringá (UEM), Universidade Estadual de Londrina (UEL), Universidade Federal do Paraná (UFPR) e Universidade Norte do Paraná (UNOPAR).

Para analisar os autores e os orientadores das dissertações e teses foram consultados os Currículos Lattes dos envolvidos. Nesta busca, foram levados em consideração os quesitos publicações em periódicos científicos, projetos de pesquisa realizados e em andamento, orientações e experiência profissional, acreditando ser este um meio confiável de análise de produção e da experiência dos pesquisadores, estabelecendo as relações que levaram cada um a pesquisar a atividade física para indivíduos com deficiência.

O período de busca ocorreu entre 21/01/2016 à 22/10/2016, por conseguinte, no levantamento estão incluídos apenas trabalhos defendidos até o início do segundo semestre de 2016. Foram inclusos apenas dissertações e teses encontrados nas bibliotecas digitais dos Programas de Pós-Graduação das instituições envolvidas. Sendo assim, existe a possibilidade de existirem trabalhos defendidos com a temática escolhida, mas, que não estão presentes neste estudo por ainda não terem sido disponibilizados nas bibliotecas digitais de suas respectivas instituições.

\section{A pesquisa em Atividade Física Adaptada no Paraná}

Como foi explicitado, no estado do Paraná existem recomendadas pela CAPES, quatro Instituições de Ensino Superior (IES) que possuem Programas de Pós-Graduação em Educação Física: Universidade Federal do Paraná (UFPR), Universidade Norte do Paraná (UNOPAR), Universidade Estadual de Maringá (UEM) e Universidade Estadual de Londrina (UEL). Ressalta-se, como indicam Soriano; Lara (2012) que o curso das últimas duas universidades é associado e será analisado de forma unificada.

Após levantamento dos dados, foi encontrado um total de 593 teses e dissertações nos Programas de Pós-graduação em Educação Física paranaenses (242 da UEL/UEL, 310 da UFPR e 41 da UNOPAR). Do total, 17 trabalhos (2,87\% do total) são relacionados à Atividade Física Adaptada (AFA). Destes, quinze são dissertações de mestrado e duas teses de doutorado, conforme pode ser visualizado na Tabela 1: 
Tabela 1: Tabela de autores, orientadores, títulos e ano de defesa - Sistematizado pelos autores.

\begin{tabular}{|c|c|c|c|c|}
\hline $\begin{array}{l}\text { IES/ } \\
\text { Dissertação } \\
\text { ou Tese }\end{array}$ & Autor (a) & Orientador (a) & Título do Trabalho & $\begin{array}{l}\text { Ano de } \\
\text { Defesa }\end{array}$ \\
\hline UFPR & & & Mestrado & \\
\hline D.1 & $\begin{array}{l}\text { Andréa Lucia Serio } \\
\text { Bertoldi }\end{array}$ & Iverson Ladewig & $\begin{array}{l}\text { A influência do uso de dicas de aprendizagem } \\
\text { na percepção corporal de crianças portadoras de } \\
\text { deficiência motora }\end{array}$ & 2004 \\
\hline D.2 & $\begin{array}{l}\text { Gisele Pereira da } \\
\text { Silva }\end{array}$ & $\begin{array}{l}\text { Ruth Eugenia Amarante } \\
\text { Cidade }\end{array}$ & $\begin{array}{l}\text { A configuração de atletas e ex-atletas } \\
\text { paraolímpicas da cidade de Curitiba }\end{array}$ & 2007 \\
\hline \multirow[t]{2}{*}{ D.3 } & Rafael Estevam Reis & $\begin{array}{l}\text { Fernando Marinho } \\
\text { Mezzadri }\end{array}$ & $\begin{array}{l}\text { Políticas públicas para o esporte paralímpico } \\
\text { brasileiro }\end{array}$ & 2014 \\
\hline & & & Doutorado & \\
\hline T.1 & $\begin{array}{l}\text { Andréa Lucia Serio } \\
\text { Bertoldi }\end{array}$ & Iverson Ladewig & $\begin{array}{l}\text { Efeito do direcionamento de atenção para } \\
\text { parâmetros do movimento no comportamento } \\
\text { motor de pessoas com deficiência física }\end{array}$ & 2012 \\
\hline \multicolumn{2}{|l|}{ UEM/UEL } & & \multicolumn{2}{|l|}{ Mestrado } \\
\hline D.4 & $\begin{array}{l}\text { Gilberto Carlos } \\
\text { Pereira da Silva }\end{array}$ & $\begin{array}{l}\text { Vanildo Rodrigues } \\
\text { Pereira }\end{array}$ & $\begin{array}{l}\text { Tempo de reação do jogador de goalball na } \\
\text { interceptação/defesa do lançamento/ataque }\end{array}$ & 2008 \\
\hline D. 5 & $\begin{array}{l}\text { Larissa Daniele } \\
\text { Rubira Strioto }\end{array}$ & José Luiz Lopes Vieira & $\begin{array}{l}\text { Análise dos padrões motores de crianças com } \\
\text { síndrome de Down na tarefa de subir escadas }\end{array}$ & 2010 \\
\hline D.6 & $\begin{array}{l}\text { Giovanna Carla } \\
\text { Interdonato }\end{array}$ & Márcia Greguol & $\begin{array}{l}\text { Prática habitual de atividade física e cuidados de } \\
\text { saúde em adolescentes com deficiência sensorial }\end{array}$ & 2011 \\
\hline D.7 & $\begin{array}{l}\text { Luana Muriel } \\
\text { Casarolli }\end{array}$ & José Luiz Lopes Vieira & $\begin{array}{l}\text { Análise cinemática e cinética do salto vertical } \\
\text { de crianças com síndrome de Down e com } \\
\text { desenvolvimentos típico }\end{array}$ & 2011 \\
\hline D.8 & $\begin{array}{l}\text { Camila Yuri } \\
\text { Kawanishi }\end{array}$ & Márcia Greguol & $\begin{array}{l}\text { Avaliação da autonomia funcional de indivíduos } \\
\text { adultos com lesão medular fisicamente ativos e } \\
\text { sedentários }\end{array}$ & 2012 \\
\hline D.9 & $\begin{array}{l}\text { Allan James de } \\
\text { Castro Bussmann }\end{array}$ & Márcia Greguol & $\begin{array}{l}\text { Avaliação da técnica de propulsão e incidência } \\
\text { de lesões de atletas praticantes de basquetebol } \\
\text { em cadeira de rodas }\end{array}$ & 2012 \\
\hline D. 10 & Vera Felicidade Dias & $\begin{array}{l}\text { Vanildo Rodrigues } \\
\text { Pereira }\end{array}$ & $\begin{array}{l}\text { O processo de aquisição de habilidades motoras } \\
\text { em indivíduos com baixa visão }\end{array}$ & 2012 \\
\hline D. 11 & $\begin{array}{l}\text { Juliana Jacques } \\
\text { Pastório }\end{array}$ & $\begin{array}{l}\text { Solange Marta Franzói } \\
\text { de Moraes }\end{array}$ & $\begin{array}{l}\text { Quantificação de carga interna de treinamento e } \\
\text { marcadores fisiológicos em atletas de goalball }\end{array}$ & 2013 \\
\hline D. 12 & Bruna Barboza Seron & Márcia Greguol & $\begin{array}{l}\text { Efeitos de dois programas de treinamento sobre } \\
\text { a capacidade cardiorrespiratória e a composição } \\
\text { corporal de jovens com síndrome de Down }\end{array}$ & 2014 \\
\hline D. 13 & $\begin{array}{l}\text { Everaldo Lambert } \\
\text { Modesto }\end{array}$ & Márcia Greguol & $\begin{array}{l}\text { Efeitos de dois programas de treinamento sobre } \\
\text { a força muscular e o equilíbrio dinâmico de } \\
\text { adolescentes com síndrome de Down }\end{array}$ & 2014 \\
\hline D. 14 & $\begin{array}{l}\text { Fernando Cordeiro } \\
\text { Vilar Mendes }\end{array}$ & Pedro Paulo Deprá & $\begin{array}{l}\text { Caracterização da cinemática de paratletas no } \\
\text { voleibol sentado }\end{array}$ & $\underline{2015}$ \\
\hline \multirow[t]{2}{*}{ D.15 } & $\begin{array}{l}\text { Eloise Werle de } \\
\text { Almeida }\end{array}$ & Márcia Greguol & $\begin{array}{l}\text { Estado de saúde, prática de atividade física } \\
\text { e composição corporal em mulheres com } \\
\text { deficiência visual no climatério e pós-menopausa }\end{array}$ & 2015 \\
\hline & & & Doutorado & \\
\hline Т.2 & Bruna Barboza Seron & Márcia Greguol & $\begin{array}{l}\text { Demandas fisiológicas do jogo de basquete } \\
\text { em cadeira de rodas: análise por deficiência, } \\
\text { classificação funcional e posição em quadra }\end{array}$ & 2016 \\
\hline
\end{tabular}


O programa de Pós-Graduação em Educação Física da UFPR começou a ofertar vagas para mestrado em 2002 e o doutorado iniciou em 2007. Por sua vez, o programa associado da UEL e UEM iniciou-se suas atividades no ano de 2006. No Banco de Dissertações e Teses da UEL visualizou-se que as primeiras defesas foram datadas em 2007 e na UEM em 2008. Este programa associado, conta também com o curso de doutorado que se iniciou no ano de 2011. Mesmo com a diferença na data de início dos programas, na UFPR apenas 4 trabalhos foram desenvolvidos sobre a temática $(1,29 \%$ do total de dissertações e teses disponibilizadas em sua biblioteca digital), enquanto na UEL/UEM foram encontradas ao todo 13 produções (5,37\% do seu total). Por sua vez, na UNOPAR nenhum trabalho relacionado com AFA foi encontrado. O que justifica a ausência do programa desta universidade nos dados, tabelas e discussões do presente artigo.

Além de ser um fenômeno recente, a Pós-Graduação em Educação Física tem revelado, conforme salientam Rigo; Ribeiro; Hallal (2011), uma enorme diversidade de temas e objetos a serem explorados. Entre as muitas possibilidades de pesquisa está a AFA (SILVA; ARAÚJO, 2012). Neste contexto é difícil afirmar se 17 dissertações/teses é um número muito pequeno para a quantidade de defesas que ocorreram no Paraná, ou se esta quantidade, dentro de uma área tão plural epistemologicamente como a Educação Física, trata-se de uma "conquista" para a referida temática.

Nesse sentido, uma das principais preocupações do presente artigo é o de mostrar o que tem sido estudado na área da AFA, quais são os seus principais objetos nas pesquisas realizadas e em que área de concentração e linhas de pesquisa os mesmos se encontram. Com o intuito de melhor compreender os principais objetos de pesquisa dentro da temática no estado do Paraná, uma caracterização de cada programa do estado se faz necessária (não foram colocadas as informações da UNOPAR pelos motivos citados anteriormente).

O programa da UFPR não se divide em áreas de concentração, apresenta apenas uma área denominada Exercício e Esporte, com um corpo docente de 21 professores, na qual se encontram três linhas de pesquisa:

- Atividade Física e Saúde;

- Comportamento Motor (extinta em 15/12/2014);

- Desempenho Esportivo;

- Esporte, Lazer e Sociedade.

Por sua vez o programa associado da UEM/UEL é composto por 38 professores. Existem 2 áreas de concentração e 5 linhas de pesquisa:

\section{Desempenho Humano e Atividade Física}

- Atividade física relacionada à saúde;

- Fatores psicossociais e motores relacionados ao desempenho humano;

- Ajustes e respostas fisiológicas e metabólicas ao exercício físico. 


\section{Práticas Sociais em Educação Física}

- Trabalho e formação em educação física;

- Práticas, políticas e produção de conhecimento em educação física.

Como visto, não existe em nenhuma das instituições uma linha de pesquisa específica relacionada à AFA e/ou suas variações. Dessa forma, os trabalhos relacionados à temática se encontram dispersos em diferentes linhas de pesquisa. Isto pode ser considerado um indicativo relacionado a porcentagem do número de investigações encontrado em Atividade Física Adaptada no universo maior na pós-graduação em Educação Física no estado do Paraná.

Na tabela 2, apresentam-se as dissertações e as teses dentro de sua respectiva linha de pesquisa e o objetivo de cada uma.

Linhas de pesquisa foram criadas e/ou modificadas ao longo dos anos, levando a discrepância entre as apresentadas anteriormente e as encontradas na Tabela2. Por exemplo, na UFPR, a linha de Comportamento Motor está presente, mas foi desativada no ano de 2014, não constando mais como linha de pesquisa no programa. Por sua vez, a linha Sociologia do Esporte e Lazer na qual esta inserido o trabalho D.3 recebeu posteriormente o nome de Esporte, Lazer e Sociedade. Em algumas dissertações do programa associado da UEM/UEL também não estão expostas em quais linhas e/ou área de concentração cada trabalho está inserido. Todavia, a problemática de cada investigação oferece um horizonte de qual enfoque epistemológico os autores seguiram.

Silva; Araújo (2012, p. 231), ao tratar do contexto brasileiro de forma global, explicam que este quadro de poucas pesquisas sobre a AFA no Brasil se dá pela "(...) recente chegada da população em condição de deficiência como sujeito de pesquisa stricto sensu, em Educação Física no Brasil". Segundo os autores, foi somente no final dos anos 1980 que surgiram as primeiras dissertações voltadas à PCD. Silva; Araújo (2012), ainda indicam em sua pesquisa que em todo o Brasil, até o ano 2008, foram localizadas um total de 88 dissertações e teses relacionadas à temática4.

4 Destas 88 dissertações e teses 4 foram escritas na década de 1980, na década de 1990 foram produzidos mais 23 e do ano 2000 até 2008 acrescentaram-se mais 61 produções (SILVA; ARAÙJO, 2012). 


\section{Tabela 2: Tabela de linhas de Pesquisa - Sistematizado pelos autores ${ }^{5}$}

\begin{tabular}{|c|c|c|}
\hline $\begin{array}{l}\text { IES/ } \\
\text { Dissertação } \\
\text { ou Tese }\end{array}$ & $\begin{array}{l}\text { Área de concentração/ } \\
\text { Linha de Pesquisa em } \\
\text { que se encontra }\end{array}$ & Problema privilegiado/ objetivo principal \\
\hline UFPR & & Mestrado \\
\hline D.1 & Comportamento Motor & $\begin{array}{l}\text { Comportamento motor de crianças com deficiência antes e pós-dicas de } \\
\text { aprendizagem }\end{array}$ \\
\hline D.2 & Comportamento Motor ${ }^{5}$ & $\begin{array}{l}\text { Configuração das atletas paralímpicas sob a ótica da teoria configuracional de } \\
\text { Norbert Elias }\end{array}$ \\
\hline \multirow[t]{2}{*}{ D.3 } & $\begin{array}{l}\text { Sociologia do Esporte } \\
\text { e Lazer }\end{array}$ & Políticas Públicas que contemplam o esporte paralímpico brasileiro \\
\hline & & Doutorado \\
\hline T.1 & Comportamento Motor & $\begin{array}{l}\text { Efeitos da prática de exercícios com direcionamento de atenção para a variabilidade } \\
\text { de parâmetros do movimento na organização motora de pessoas com lesão medular } \\
\text { torácica durante a realização de uma ação funcional de membro superior }\end{array}$ \\
\hline UEM/UEL & & Mestrado \\
\hline D.4 & $\begin{array}{l}\text { Estudos do movimento } \\
\text { humano }\end{array}$ & $\begin{array}{l}\text { Comportamento motor de jogadores de goalball cegos e com deficiência visual, } \\
\text { de ambos os sexos, para avaliar a influencia do tempo de reação na eficiência das } \\
\text { ações de defesa }\end{array}$ \\
\hline D.5 & $\begin{array}{l}\text { Estudos do movimento } \\
\text { humano }\end{array}$ & $\begin{array}{l}\text { Analisar as características cinemáticas e cinéticas do subir escada de crianças com } \\
\text { síndrome de Down e compará-las com crianças com desenvolvimento típico. }\end{array}$ \\
\hline D.6 & $=$ & $\begin{array}{l}\text { Analisar os níveis de atividade física e as condições de saúde em adolescentes com } \\
\text { deficiência sensorial (visual ou auditiva) da cidade de Londrina - PR }\end{array}$ \\
\hline D.7 & $\begin{array}{l}\text { Estudos do movimento } \\
\text { humano }\end{array}$ & $\begin{array}{l}\text { Analisar as características cinemáticas e cinéticas do salto vertical de crianças com } \\
\text { síndrome de Down e com desenvolvimento típico. }\end{array}$ \\
\hline D.8 & $=$ & $\begin{array}{l}\text { Avaliar a qualidade de vida e a autonomia funcional para realização de atividades } \\
\text { da vida diária em pessoas com lesão medular fisicamente ativas e sedentárias }\end{array}$ \\
\hline D.9 & $=$ & $\begin{array}{l}\text { Avaliar a técnica de propulsão e a incidência de lesões de atletas de basquetebol } \\
\text { em cadeira de rodas. }\end{array}$ \\
\hline D.10 & $=$ & $\begin{array}{l}\text { Analisar o efeito de uma proposta de estimulação motora em indivíduos de } 6 \text { a } 12 \\
\text { anos com baixa visão }\end{array}$ \\
\hline D.11 & $\begin{array}{l}\text { Ajustes e respostas } \\
\text { fisiológicas e metabólicas } \\
\text { ao exercício físico }\end{array}$ & $\begin{array}{l}\text { Quantificar de carga interna de treinamento para deficientes visuais e analisar } \\
\text { respectivamente a demanda fisiológica em treinos da modalidade goalball }\end{array}$ \\
\hline D.12 & $=$ & $\begin{array}{l}\text { Verificar os efeitos de dois programas de treinamento sobre a capacidade } \\
\text { cardiorrespiratória e a composição corporal de jovens com síndrome de Down }\end{array}$ \\
\hline D.13 & $=$ & $\begin{array}{l}\text { Verificar o efeito de dois programas de treinamento (aeróbio e resistido) sobre a } \\
\text { força muscular e o equilíbrio de adolescentes com síndrome de Down }\end{array}$ \\
\hline D. 14 & $\begin{array}{l}\text { Desempenho Humano e } \\
\text { Atividade Física }\end{array}$ & $\begin{array}{l}\text { Caracterizar a cinemática linear de paratletas no voleibol sentado durante a } \\
\text { situação real de jogo e a cinemática angular da postura corporal na realização do } \\
\text { fundamento base de deslocamento sentado }\end{array}$ \\
\hline \multirow[t]{2}{*}{ D.15 } & $=$ & $\begin{array}{l}\text { Avaliar o estado de saúde, a composição corporal, o nível de atividade física, e } \\
\text { aspectos relacionados ao climatério de mulheres com deficiência visual no período } \\
\text { de climatérios e pós-menopausa. }\end{array}$ \\
\hline & & Doutorado \\
\hline T.2 & $=$ & $\begin{array}{l}\text { Investigar aspectos relacionados às demandas fisiológicas durante partidas de } \\
\text { basquete em cadeira de rodas }\end{array}$ \\
\hline
\end{tabular}

5 Apesar de estar inserida na linha de pesquisa de Comportamento Motor, a pesquisa tem suas bases epistemológicas fundamentada na sociologia, especificamente na teoria configuracional do sociólogo alemão Norbert Elias. 
Na pesquisa de Silva; Araújo (2012) se encontra um gráfico que distribui as 88 teses e dissertações nas instituições com programas de mestrado e doutorado em Educação Física que apresentaram ao menos um trabalho relacionado com Atividade Física Adaptada (SILVA; ARAÙJO, p.229). Do total, 53 foram localizados na UNICAMP; 11 na UFRGS; 6 na USP; 4 na UCB e UGF; 3 na UNESP e UFSC; e 2 na UDESC e na UFPR. Como visto pelos números apresentados que se trata de um tema recente, no qual a maioria dos pesquisadores procurou inicialmente, segundo Silva e Araújo (2012, p.231), “conhecer esse corpo e o movimento por ele produzido (medir, avaliar, testar), além das implicações provenientes da deficiência, ou seja, um sujeito novo que precisava ser desvelado pela pesquisa".

Os números mais específicos coletados neste artigo, assim como os mais globais apresentados por Silva; Araújo (2012), não fogem à realidade da produção científica em Educação Física realizada no Brasil, pois esta área, conforme salientam Manoel; Carvalho (2011), Rigo; Ribeiro; Hallal (2011) e Moraes e Silva et al. (2017), apresenta sua raiz epistemológica nas ciências naturais. Silva; Araujo (2012) ainda lembram que a forma como a pessoa com deficiência foi incluída nas pesquisas passou a ganhar novos contornos ao longo dos anos. Enquanto nos primeiros trabalhos de mestrado e doutorado se via esse grupo somente como um objeto de estudo e/ou como um possível atleta, na década de 2000 já se ampliava um pouco este olhar. As pesquisas procuravam conhecer estes indivíduos, seus sentimentos, possibilidades, entre outros aspectos. Essa transformação, na opinião dos autores, "deu voz" os indivíduos com deficiência, ou melhor, colocaram em evidência seus anseios que começaram a ser ouvidos em vez de ignorados por parte da esfera acadêmica.

Como apontado anteriormente, os Programas de Pós-Graduação em Educação Física no Paraná são muito recentes. Consequentemente, a pesquisa relacionada à AFA ainda é bastante tímida. Porém, a lista apresentada na Tabela 2 retrata que as instituições paranaenses, mesmo em escala menor, seguem a lógica mias global levantada por Silva; Araújo (2012), visto que a maioria dos trabalhos tem como objetivo estudar o comportamento, o controle e a aprendizagem motora das pessoas com deficiência, ou seja, buscam compreender e conhecer o indivíduo, seu corpo e seu movimento.

Pode-se notar que as pesquisas, em sua maioria, optam por explorar com objeto de pesquisa um determinado tipo de deficiência. Portanto, um dado que não pode ser desconsiderado na caracterização das dissertações/teses aqui relacionadas refere-se ao tipo de deficiência explorada em cada uma das investigações. Atualmente, de forma generalizada, as deficiências são divididas em 4 tipos: Auditiva, Visual, Física e Intelectual. De acordo com esta classificação, os trabalhos catalogados se dividem da seguinte forma: 
maio/2018

Tabela 3: Dissertações e Teses por tipo de deficiência - Sistematizado pelos autores.

\begin{tabular}{lc}
\hline Tipo de Deficiência & Quantidade de Dissertações e Teses encontradas \\
\hline Deficiência Física & 6 \\
Deficiência Visual & 4 \\
Deficiência Auditiva & 0 \\
Deficiência Intelectual & 4 \\
Deficiências Sensoriais & 1 \\
Sem tipo de Deficiência específica & 2 \\
\hline
\end{tabular}

Os dados coletados revelam certo equilíbrio na divisão dos trabalhos em três tipos deficiência, 6 estão voltados para indivíduos com deficiência física, 4 com intelectual, 4 se voltam para aqueles com deficiência visual e somente uma pesquisa envolveu a sensorial. Apesar dos indivíduos com deficiência auditiva terem sido as primeiras a serem inclusas na cena esportiva e de atualmente existirem jogos e competições exclusivas para surdos (WINNICK, 2004) a pesquisa em AFA voltada a essa tipologia de deficiência é nula nas pesquisas em Educação Física no Paraná.

Os 2 trabalhos que não apresentaram um tipo específico de deficiência, foram dissertações defendidas na UFPR e delimitaram de certa forma a sua pesquisa ao esporte paralímpico, que por sua vez engloba atletas com deficiência física, visual e intelectual. Apesar disto, seus objetivos não estavam limitados a estas questões.

\section{Os agentes da produção em Atividade Física Adaptada}

O próximo passo do presente artigo é adentrar na compreensão dos agentes envolvidos no processo de produção das dissertações e teses, ou seja, os orientadores e orientandos. Afinal, conforme lembram Pereira da Silva; Gonçalves-Silva; Moreira (2014) são estes indivíduos os responsáveis pela maior parte da produção do conhecimento em Educação Física no Brasil. No total foram encontrados 15 diferentes autores sob a orientação de 8 docentes. O Currículo Lattes de cada um deles foi analisado minuciosamente para encontrar o "pano de fundo" de suas pesquisas. Dos 15 orientandos, apenas um não disponha de Lattes, portanto dos 14 currículos encontrados pode-se retirar os seguintes dados (considerando que nem todos os currículos estavam atualizados):

- 10 autores trabalham e/ou já trabalharam com esportes para PCD, sendo que 2 são fisioterapeutas e já trabalharam com reabilitação voltada e este grupo;

- 5 possuem o total das suas publicações relacionadas a AFA e outros 3 têm a maior parte da sua produção ligada a temática. Dos 5 que tem sua publicação total voltada para AFA 1 publicou somente 1 artigo, outro 2 artigos e por fim o terceiro possui 3 publicações;

- 4 autores não possuem nenhum artigo ou livro/capítulo de livro publicados na área. 
Dos 8 orientadores apenas duas docentes têm como objeto de pesquisa principal a AFA - Profa. Dra. Marcia Greguol (UEL) e Profa. Dra. Ruth Eugênia Amarante Cidade (UFPR) - os outros 6 têm como foco principal outras áreas da Educação Física. Destaca-se a produção de Marcia Greguol, que dos seus 43 artigos publicados, apenas 8 não envolvem o temática. A mesma já organizou 2 livros voltados ao assunto e escreveu 8 capítulos de livros. Inclusive das 15 dissertações e teses catalogadas no presente artigo, 7 foram orientados pela docente, resultando em 1 tese e 6 dissertações. Por sua vez, Ruth Eugenia Amarante Cidade tem todos os seus materiais publicados relacionados com AFA, são no total 6 livros, 12 artigos e 12 capítulos em livros. Porém, atualmente a docente não se encontra credenciada no Programa de Pós-Graduação da UFPR. Condição que explica a única orientação de mestrado realizada pela referida professora, que foi finalizada no ano de 2007.

Como já comentado anteriormente, os outros 6 orientadores não têm como foco central de pesquisa a AFA. Contudo, incluíram a temática no escopo de seus projetos de pesquisa, passando a orientar alunos de mestrado e/ou doutorado sobre o assunto. Um dado importante encontrado na análise dos currículos dos orientandos é que a maioria já tinha um envolvimento com a temática, principalmente por terem dado aula e/ou serem técnicos de esportes paralímpicos em instituições como escolas especiais e/ou associações para PCD. Fator que justifica os projetos desenvolvidos sob a orientação de professores que não são desta mesma área. Somente em um caso, na dissertação de Juliana Jacques Pastório, é que não foi encontrada nenhuma relação com a AFA, nem no currículo da orientanda e nem de sua orientadora a Profa. Dra. Solange Marta Franzói de Moraes (UEM). Os outros orientadores e orientandos em algum momento da sua trajetória profissional e acadêmica já tiveram algum contato com AFA e/ou desenvolveram projetos de pesquisa na área.

Outro ponto que chama a atenção na análise dos agentes é que somente 8 docentes estiveram vinculados ao processo de orientação de dissertações e teses sobre a temática. Contudo, os professores Dr. Iverson Ladewig e Dra. Ruth Eugenia Amarante Cidade, apesar de ainda serem professores da UFPR, não são mais credenciados ao Programa de Pós-Graduação em Educação Física. Já no caso do Prof. Dr. Vanildo Rodrigues Pereira (UEM), o mesmo se aposentou recentemente e por isso diminuiu consideravelmente sua carga de orientação junto ao programa associado da UEM/UEL. Tal quadro mostra como a AFA ainda não se encontra no horizonte de pesquisa da maior parte dos professores credenciados aos Programas de Pós-Graduação em Educação Física do Estado do Paraná.

\section{CONCLUSÕES}

Ao concentrar os esforços investigativos nos Programas de Pós-Graduação em Educação Física do Estado do Paraná tinha-se como intento selecionar as dissertações e teses que são, pelo menos no plano das ideias, trabalhos que despendem de um maior tempo de realização e como consequência, apresentam análises mais aprofundadas e cuidadosas. Essa delimitação permitiria iniciar um esforço investigativo que serviria de base para pesquisas futuras mais abrangentes e detalhadas. 
Como visto os Programas de Pós-Graduação em Educação Física do Estado do Paraná são relativamente recentes. Desta forma é natural que ainda não exista um grande número de pesquisas direcionadas a AFA, devido principalmente a diversidade epistemológica existente na área da Educação Física. Porém, se for levado em consideração a quantidade de produção, e não mais o tempo de existência como critério analítico, pode-se afirmar que, proporcionalmente, existem poucas teses em dissertações relacionadas à AFA produzidos nas universidades paranaenses. Neste número diminuto de trabalhos, nenhum está voltado a atividades físicas para pessoas com deficiência auditiva, o que revela um objeto ainda não explorado pelas universidades paranaenses.

Em relação aos agentes, percebe-se que aproximadamente $67 \%$ dos pesquisadores têm alguma relação com a área analisada, ou seja, pode-se considerar que as experiências diversas com a área levaram ao interesse pela pesquisa e em alguns casos o envolvimento do orientador com a área influenciou para que autores que não tinham esta relação pesquisas sobre AFA. Por sua vez, o maior número de orientadores não demonstram grande envolvimento com a AFA, com exceção das duas professoras que além de atuarem mais contundentemente com a área tem uma tradição de produção de artigos científicos e livros sobre a temática.

Por fim, o presente artigo traçou o panorama da produção em Atividade Física Adaptada dos Programas de Pós-Graduação em Educação Física no Estado do Paraná, para dessa forma poder entender melhor quem produz e o que se produz referente à área. A título de conclusão o artigo aponta que existe a necessidade de um olhar mais atento a pesquisa na AFA, principalmente com outros enfoques epistemológicos que não o do desenvolvimento e comportamento motor. Tal pluralidade na forma do fazer ciência possibilitaria que a temática fosse melhor explorada e compreendida no cenário acadêmico brasileiro. Ainda assim, as conclusões levantadas, permitem compreender uma realidade específica, de um grupo específico, que revelam uma parte da produção científica paranaense e deram um vislumbre de uma pesquisa que pode ser ampliada para abranger todo o cenário nacional e internacional e ser atualizada constantemente.

\section{REFERÊNCIAS}

ARAÚJO, P. F. Desporto Adaptado no Brasil: origem, institucionalização e atualidade. 1997. Tese (Doutorado em Educação Física) - Faculdade de Educação Física, Universidade Estadual de Campinas, Campinas.

CAPES. Cursos Recomendados. Disponível em: <www.capes.gov.br>. Acesso em: 03 de março de 2016.

FURTADO, H. L.; NAMAN, M. Formação do pesquisador em educação física: análises epistemológicas. Pensar a Prática, Goiânia, 2014; 17 (3): p.751-765.

GARCIA, L. et al. A inserção da subárea de Atividade Física e Saúde nos Programas de Pós-Graduação em Educação Física no Brasil. Revista Brasileira de Atividade Física e Saúde, Pelotas, 2014; 19 (2): p. 215-222. 
GIL, A C. Métodos e técnicas de pesquisa social. São Paulo: Atlas; 1999.

GORLA, I. Educação física adaptada: o passo a passo da avaliação. São Paulo: Editora Phorte; 2008.

MANOEL, E J; CARVALHO, Y M. Pós-graduação na educação física brasileira: a atração (fatal) para a biodinâmica. Revista Educação e Pesquisa, São Paulo, 2011; 37(2): p. 389-406.

MIRANDA, M. L. J.; BOMFIM, A. B. C.; SANTOS SILVA, S. A. P. S. Programa de PósGraduação em Educação Física da Universidade São Judas Tadeu. Revista Brasileira de Atividade Física e Saúde, Pelotas, 2013; 17 (5): p. 341-346.

MORAES E SILVA, Marcelo et al. Pós-graduação em Educação Física: apontamentos sobre o livro "Dilemas e desafios da pós-graduação em Educação Física". Journal of Physical Education, Maringá, v. 28, n. 1, e2840, 2017.

PEREIRA DA SILVA, J. V.; GONÇALVES-SILVA, L. L.; MOREIRA, W. W. Produtivismo na pós-graduação. Nada é tão ruim, que não possa piorar. É chegada a vez dos orientandos! Movimento, Porto Alegre, 2014; 20(4): p. 1423-1445.

PEREIRA DA SILVA, J. V. Políticas Públicas de Esporte/Lazer e in(ex)clusão de pessoas com deficiência. Campo Grande: Editora UFMS; 2015.

REIS, R. E. Políticas Públicas para o esporte paralímpico brasileiro. 2014. Dissertação (Mestrado em Educação Física) - Programa de Pós-Graduação em Educação Física. Universidade Federal do Paraná, Curitiba.

RIGO, L. C.; RIBEIRO, G. M.; HALLAL, P. C. Unidade na diversidade: desafios para a Educação Física no século XXI. Revista Brasileira de Atividade Física e Saúde, Pelotas, 2011; 16 (4): p. 339-345.

ROSA, S. P.; LETA, J. Tendências atuais da pesquisa brasileira em Educação Física. Parte 2: a heterogeneidade epistemológica nos programas de pós-graduação. Revista Brasileira de Educação Física e Esporte, São Paulo, 2011; 25 (1): p. 7-18.

SILVA, R. F; SEABRA JÚNIOR, L; ARAÚJO, P. F. Educação física adaptada no Brasil: da história a inclusão educacional. São Paulo: Editora Phorte; 2008.

SILVA, R. F.; ARAÚJO, P. F. Os caminhos da pesquisa em atividade motora adaptada. São Paulo: Phorte; 2012.

SORIANO, J. B.; LARA, L. M. Pós-Graduação em Educação Física UEM/UEL: experiências e desafios de um programa associado. Revista Brasileira de Atividade Física e Saúde, Pelotas, 2012; 17 (1): p. 69-74.

SOUZA, J. V. Dimensões da Organização de um Centro de Atividades Motoras Adaptadas para Pessoas com Deficiência com base na Extensão Universitária. In: RODRIGUES, D. (org.). Atividade Motora Adaptada: a alegria do corpo. São Paulo: Artes Médicas; 2006. p. 131-140.

SOUZA, D. L., MORAES E SILVA, M.; MOREIRA, T. S. O perfil da produção científica online em português relacionada às modalidades olímpicas e paralímpicas. Movimento. Porto Alegre, 2016; 22 (4): p. 1105-1120. 
maio/2018

TAVARES, O. Desafios e Dilemas da pós-graduação em Educação Física: os estudos socioculturais. In: RECHIA, S. et al. (orgs.). Dilemas e Desafios da Pós-Graduação em Educação Física. Ijuí: Ed. UNIJUì, 2015, p. 219-234.

WINNICK, J. P. Educação física e esportes adaptados. Barueri, SP: Manole; 2004.

Recebido em: Março/2017

Aprovado em: Julho/2017 